\title{
Large vessel disease as a potentially treatable cause of devastating critical digital ischaemia in systemic sclerosis
}

\author{
Ashraful Haque $^{1} \cdot$ Trevor Cleveland $^{2} \cdot$ Lewis Powell $^{1} \cdot$ Sarah Stephenson ${ }^{1} \cdot$ Michael Hughes $^{1} \cdot$ Rachael Kilding $^{1}$
}

Received: 28 March 2020 / Revised: 9 April 2020 / Accepted: 21 April 2020 / Published online: 8 May 2020

(C) International League of Associations for Rheumatology (ILAR) 2020

A 60-year-old lady with known limited cutaneous SSc (anti-centromere antibody positive) and a history of severe digital vascular disease presented with progressive digital vascular ischaemia. Her history included bilateral (periarterial) sympathectomy and digital amputation. She had no modifiable cardiovascular risk factors and was taking sildenafil for SSc-digital vasculopathy.

At presentation, there was ulceration of tip of the left index finger and thumb, with progressive necrosis (a) (Fig. 1). She was in significant pain and received a 5day course of intravenous iloprost. Despite this, she developed very tender swelling of her left wrist and forearm with absent radial and brachial pulses.

A more proximal cause for compromised flow was suspected, and therefore, an urgently requested arterial Duplex scan demonstrated an occluded radial artery, with reversed flow in the ulnar artery. Flow in the brachial artery was noted to be severely damped. Therefore, computerised tomography angiography (CTA) was performed with a view to therapeutic intervention.

CTA demonstrated a short occlusion of the left subclavian artery (b), which was confirmed by a catheter angiogram (c), performed prior to placement of a stent (d) to successfully relieve the obstruction. Subsequently, her clinical condition improved with reduced pain and limitation of ischaemic tissue loss.

Critical digital ischaemia in SSc is a medical emergency because early recognition of proximal (large) vessel disease can potentially be amenable to tissue-saving revascularisation [1-3]. An increased risk of macrovascular disease has been reported in SSc, in particular, in those with limited disease and positive anti-centromere antibodies (like our patient) [1-3]. Other potential causes include (but are not limited to) inflammation (e.g. vasculitis), infection and embolism [3]. Clinicians must maintain a high index of suspicion and always actively consider large vessel disease in SSc-related critical digital ischaemia.

Rachael Kilding

R.Kilding@nhs.net

1 Department of Rheumatology, Royal Hallamshire Hospital, Sheffield Teaching Hospitals NHS Foundation Trust, Sheffield, UK

2 Sheffield Vascular Institute, Northern General Hospital, Sheffield Teaching hospitals NHS Foundation Trust, Sheffield, UK 

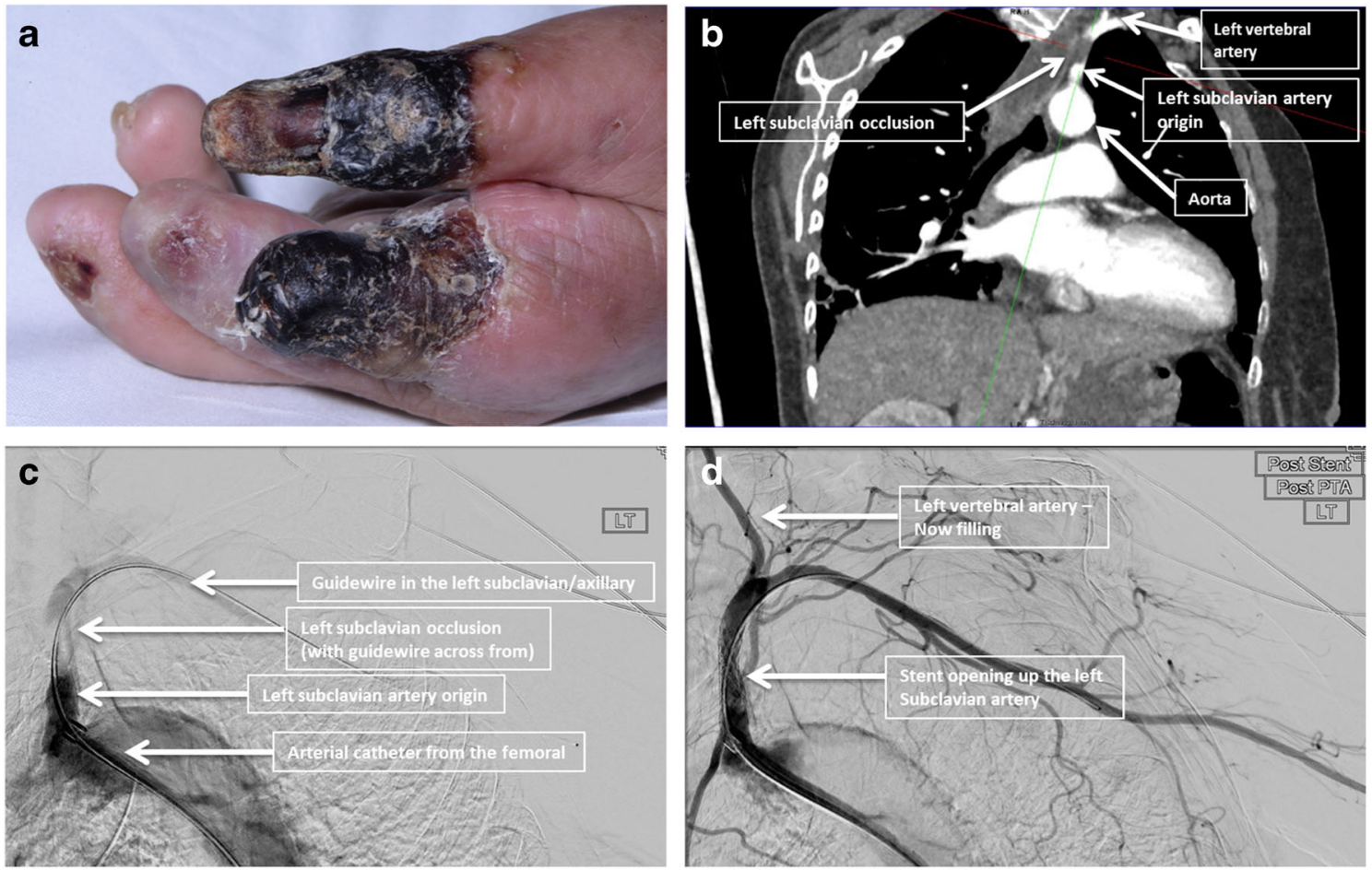

Fig. 1 Ulceration and necrosis of the left index finger and thumb (a), occlusion of the left subclavian artery on CTA (b) and catheter angiogram (c) which was stented (d)

\section{Compliance with ethical standards}

\section{Disclosures None.}

\section{References}

1. Hughes M, Allanore Y, Chung L, Pauling JD, Denton CP, MatucciCerinic M (2020) Raynaud phenomenon and digital ulcers in systemic sclerosis. Nat Rev Rheumatol 16:208-221. https://doi.org/10. 1038/s41584-020-0386-4
2. Hughes M, Ong VH, Anderson ME, Hall F, Moinzadeh P, Griffiths B, Baildam E, Denton CP, Herrick AL (2015) Consensus best practice pathway of the UK Scleroderma Study Group: digital vasculopathy in systemic sclerosis. Rheumatology (Oxford) 54(11):20152024

3. Sharp CA, Akram Q, Hughes M, Muir L, Herrick AL (2016) Differential diagnosis of critical digital ischemia in systemic sclerosis: report of five cases and review of the literature. Semin Arthritis Rheum 46(2):209-216

Publisher's note Springer Nature remains neutral with regard to jurisdictional claims in published maps and institutional affiliations. 